\title{
MEDIAÇÃO E CONCILIAÇÃO: a necessária previsão de um real incentivo
}

\author{
Gláucio Maciel Gonçalves*
}

Fernanda Loures de Oliveira*

RESUMO: O escopo do presente trabalho é demonstrar a necessidade de estímulo efetivo à conciliação e mediação, para superar a cultura de litigância, já que as estatísticas demonstram que a simples previsão de uma fase destinada à tentativa de composição consensual, no processo civil, não é suficiente para criar real incentivo ao acordo. Utilizase como metodologia a revisão bibliográfica, examinando-se obras de relevo e estatísticas recentes. Promovem-se, também, comparações entre as leis brasileira, italiana e portuguesa. A relevância do estudo decorre da importância do fomento aos métodos consensuais de resolução de conflitos para reduzir a sobrecarga da Justiça, garantindo eficiência.

PALAVRAS-CHAVE: Meios Alternativos de Resolução de Conflitos. Mediação. Conciliação. Normas Indutoras. Sanção Premial.

\section{MEDIATION AND CONCILIATION: the necessity of a real incentive}

ABSTRACT: This paper seeks to demonstrate the necessity to establish actual incentives to conciliation and mediation in order to overcome the culture of litigation. Court numbers show that the mere prediction of a phase for attempting a consensual solution in the civil procedure is not enough to create a real incentive for agreement. The methodology is based on literature review, the exam of important works and recent court numbers. We also compare the Brazilian, Italian and Portuguese legislation. The relevance of the study derives from the importance of promoting consensus-based methods to reduce the current overload of the Judiciary, ensuring efficiency.

\footnotetext{
* Mestre e Doutor em Direito pela Universidade Federal de Minas Gerais (UFMG), com estudos de pósdoutorado pela Albert-Ludwigs-Universität, em Freiburg, Alemanha. Professor associado de processo civil da UFMG, é membro permanente da pós-graduação, e exerce o cargo de juiz federal em Belo Horizonte/MG.

* Doutoranda em Direito pela Universidade Federal de Minas Gerais (UFMG). Mestra em Direito pelo Centro Universitário de Brasília.
} 
KEYWORDS: Alternative Means of Dispute Resolution. Mediation. Conciliation. Inductive Rules. Prize Sanction.

\section{INTRODUÇÃO}

A finalidade precípua do presente estudo é fundamentar a necessidade de se estabelecer um incentivo palpável ao uso dos métodos adequados de solução de conflitos representados pela conciliação e pela mediação, baseada no reconhecimento de que a simples previsão legislativa de seu emprego prático não é suficiente para amainar a cultura litigante existente no país.

Para tanto, utiliza-se como metodologia de pesquisa a revisão bibliográfica, examinando-se as obras de especial relevo para o tratamento da matéria, as estatísticas recentes do Judiciário nacional, a ordem jurídica em vigor e a comparação com sistemas judiciais afins, especificamente, o sistema italiano e o modelo português, de modo a fornecer as balizas indispensáveis para justificar a proposta de alteração legislativa sugerida ao final.

O artigo inicia-se com a apresentação dos números do Judiciário brasileiro, de modo a demonstrar a existência de uma forte cultura de litigância. Afirma-se, ademais, que não se trata de característica exclusiva do Brasil, visto que a hostilidade em relação aos métodos consensuais de resolução das controvérsias também pode ser sentida na Itália.

Em seguida, passa-se a examinar os diversos incentivos dados pelas legislações brasileira, italiana e portuguesa, à adoção da mediação e da conciliação, na tentativa de se operar uma mudança de paradigmas.

Por fim, analisam-se as normas tributárias indutoras como forma de sanção premial e seu potencial impacto de fomento à mediação e à conciliação.

Com a atual sobrecarga do sistema judicial brasileiro, é crucial encontrar mecanismos destinados a impulsionar o uso de métodos consensuais de resolução de conflitos, para que se alivie a Justiça estatal das questões que possam ser resolvidas antecipadamente.

Por conseguinte, a relevância da pesquisa decorre da imprescindibilidade de se considerar outras formas de indução, além da simples imposição legal de uma fase de mediação e conciliação, que tem lugar apenas caso não haja manifestação expressa quanto 
ao desinteresse das partes na tentativa de composição voluntária. Acredita-se que o uso de sanções premiais, como medidas de incentivo à consensualidade, criariam condições psicológicas favoráveis ao acordo.

\section{A CULTURA DE LITIGÂNCIA COMO ENTRAVE PARA A AUTOCOMPOSIÇÃO}

A crise do Poder Judiciário emergiu como um dos temas centrais da ciência processual nos últimos anos, em decorrência da excessiva morosidade da prestação jurisdicional, do aumento significativo da litigiosidade após a promulgação da Constituição de 1988 e da permanência do processo estatal como principal meio de resolução de conflitos, o que ocasionou a atual sobrecarga de processos (GONÇALVES; BRITO, 2015, p. 292-293 e 324). Nesse contexto, é possível falar em uma crise de efetividade, já que não adianta garantir formalmente o acesso à justiça sem que o sistema seja, de fato, efetivo (GONÇALVES, 2003, p. 55).

Deveras, o Poder Judiciário finalizou o ano de 2015 com cerca de 74 milhões de processos em tramitação, "mesmo tendo baixado 1,2 milhão de processos a mais do que o quantitativo ingressado (índice de atendimento à demanda de 104\%), o estoque aumentou em 1,9 milhão de processos (3\%) em relação ao ano anterior”, atingindo a marca de $72,2 \%$ de taxa de congestionamento bruta. Acresça-se a isso o fato de que o tempo médio de tramitação de processos pendentes no primeiro grau de jurisdição, excetuados os Juizados Especiais, foi de dois anos e onze meses para o processo de conhecimento, e de oito anos e seis meses para o processo de execução (BRASIL, 2016, p. $42-49$ e 71$)$.

Os dados são ainda mais sensíveis ao se tomar em conta o ano de 2016. O número de processos em tramitação aumentou para 79,7 milhões, ao passo que o índice de atendimento à demanda reduziu-se para 100,3\%. Assim, ampliou-se o estoque em 2,7 milhões de processos, o que representa um acréscimo de 3,6\% em comparação com o ano de 2015. Por conseguinte, a taxa de congestionamento bruta subiu para 73\% (BRASIL, 2017, p. 67 e 79).

Entretanto, o tempo médio de tramitação processual foi reduzido para um ano e quatro meses na fase de conhecimento (da autuação ao julgamento de mérito) e para quatro anos e seis meses na fase de execução. É difícil, porém, avaliar se se trata de real 
avanço ou de simples alteração na metodologia de pesquisa, já que, nas estatísticas do Conselho Nacional de Justiça referentes ao ano de 2016, suprimiu-se a observação de acordo com a qual, no cálculo temporal de tramitação, não seriam considerados os procedimentos dos Juizados Especiais (Ibid., p. 183).

No ano de 2017, por sua vez, a estatística se torna alarmante: o número de processos em tramitação subiu para 80,1 milhões. Embora o índice de atendimento à demanda tenha aumentado para 106,5\% e a taxa de congestionamento bruta tenha sofrido uma leve queda, chegando a 72,1\%, o estoque foi incrementado com mais 244 mil processos, o que representa uma variação de $0,3 \%$ relativamente ao saldo de 2016. Ademais, o tempo médio de tramitação processual aumentou: no primeiro grau de jurisdição, passou a ser de um ano e sete meses, para o processo de conhecimento, e de quatro anos e onze meses para o processo de execução — sem informação sobre eventual exclusão dos procedimentos dos Juizados Especiais, o que, como ressaltado acima, pode ter ensejado uma redução artificial em relação aos números de 2015 (BRASIL, 2018, p. 73,91 e 148).

Os dados apresentados demonstram a necessidade de se amenizar a cultura de litigiosidade instalada no Brasil, restabelecendo o diálogo como método de (re)compreensão do passado, pela afirmação da justiça restaurativa, pautada em procedimentos que incluam a mediação e a conciliação. $\mathrm{O}$ foco passa a ser, assim, as pessoas envolvidas e o porvir e não o conflito e os fatos que o originaram; outrossim, afasta-se a ideia de necessária representação processual, apoiando-se no diálogo direto, conduzido por um facilitador, que atue de modo justo e imparcial (ORSINI; NEVES, 2012, p. 30-32 e 34-36).

No cenário apresentado, esperar que o Estado atribua ao Judiciário a estrutura de que necessita é uma utopia, já que também são importantes as necessidades de outras áreas e serviços públicos, e igualmente aflitiva a escassez por estes sofrida. A solução demanda criatividade e a utilização de mecanismos mais ágeis de resolução de conflitos, incluindo as conciliações, mediações e arbitragens (AMORIM, 2011, p. 11).

Não seria mesmo possível que o processo permanecesse à margem das transformações operadas no Direito Público em geral, que passa a ser invadido pelas ideias da consensualidade e da eficiência, garantindo-se maior espaço à participação dos interessados na resolução das crises de direito material, para que se solucionem em tempo 
razoável e de modo efetivo (ANDRADE, 2016, p. 49-50). Reforça-se, portanto, o policentrismo decisório, rompendo-se o autoritarismo e dando margem para o empoderamento das partes e o exercício de sua autonomia privada (ARAÚJO, 2016, p. 92).

Não por outro motivo, a vasta utilização da arbitragem e também a difusão da conciliação e da mediação levaram destacados doutrinadores a preferir o termo "meio adequado (ou mais adequado) de solução de litígios" no lugar da fórmula tradicional “meios alternativos" (BONATO, 2015, p. 348, nota 35).

Em verdade, o uso da expressão "meios alternativos" denota o fato de que o exercício da jurisdição pelo juiz estatal tem sido, na realidade ocidental, o meio normal, rotineiro e ordinário de pacificação social. No entanto, "a ótica sob a qual se fala em meios alternativos em contraposição ao meio ordinário é eminentemente cultural" e decorre da noção de estado intervencionista (CALMON, 2015, p. 80).

Constrói-se, por essa via, a aparente naturalidade da solução do conflito pela via judicial, embora, sob o ponto de vista histórico, o meio mais antigo de solução de controvérsias não seja o judicial. Nesse contexto, a terminologia mais correta é a que classifica tais métodos como meios adequados de pacificação social, considerando um sistema multiportas, em que o exercício da jurisdição é apenas mais uma das possibilidades existentes, mas não a única ou a principal (Ibid., p. 81-82).

Na mesma linha, tomando, porém, como base o sistema italiano, Guido Alpa considera que as dificuldades de funcionamento prático do sistema de mediação são principalmente relacionadas à tradição do contraditório; e a um nível de conhecimento da mediação muitas vezes limitado (ALPA, 2017, p. 799-800).

Michele Angelo Lupoi descreve a atitude particularmente hostil com que a advocacia recepcionou a previsão original da mediação como pressuposto processual, em 2010, na Itália, passando a defender sua inconstitucionalidade — efetivamente reconhecida em 06 de dezembro de 2012, pelo Tribunal Constitucional, apenas em decorrência de um aspecto formal de edição do normativo, que não afetou o instituto da mediação em si. O autor completa ao mencionar que, meses depois, com o Decreto 69 de 2013, reeditou-se a normativa, com algumas inovações significativas, para superar as principais críticas dirigidas ao texto original e fazer o instituto mais palatável (ou menos indigesto) à classe forense (LUPOI, 2016, p. 13-14). 
Esse breve relato confirma o fato de que a mentalidade generalizada de indivíduos, profissionais e empresas privadas não cultivava empatia pela mediação. Todavia, o testemunho de sucesso da mediação e da conciliação, em setores específicos, em um contexto mais recente, pode e deve ser considerado pelos céticos, como indicativo de que é possível sua expansão, pela formação de uma cultura conciliatória (ALPA, 2017, p. 807).

No Brasil, a situação não diverge. Afinal, alterações legislativas, por mais relevantes que sejam, não impactam necessariamente em equivalente mudança social, havendo necessidade de certo tempo e esforço para que a cultura de delegação da resolução de controvérsias à autoridade judicial e a "guerra entre as partes" sejam transformadas (ARAÚJO, 2016, p. 101).

Nesse ponto, há de se considerar o fato de que o bom uso da mediação delegada e das boas práticas conciliatórias também reside no percurso de formação da classe forense e da magistratura, exigindo uma mudança cultural de todas as categorias envolvidas (ALPA, 2017, p. 809-810).

É preciso alterar o método corrente de ensino jurídico, "moldado pelo sistema da contradição (dialética) que forma guerreiros, profissionais combativos e treinados para a guerra, para a batalha, em torno de uma lide", da qual somente pode sair um vencedor (BACELLAR, 2012b, p. 90). O modelo adversarial não pode mais pautar a estrutura processual brasileira, nem o modo de formação dos juristas (BACELLAR, 2012a, p. 87).

Portanto, pode-se afirmar que, em parte, é das instituições de ensino jurídico do país a responsabilidade pelo processo de alteração da cultura litigiosa por costumes conciliatórios, o que representa uma via fundamental para a redução da crescente demanda judicial, que compromete a eficiência do sistema de justiça (DEOLINDO, 2012, p. 83).

No entanto, o problema não se restringe à classe forense, e não será resolvido apenas pela modificação do currículo das faculdades de Direito do país, já que deve partir das próprias partes a vontade de realização do acordo.

Por certo, não é possível ao advogado, ainda que devidamente instruído acerca das vantagens da composição consensual, impor um acordo ao seu constituinte, motivo pelo qual se faz necessário o desenvolvimento de uma cultura autocompositiva. 


\section{INCENTIVOS À MEDIAÇÃO E À CONCILIAÇÃO COMO MUDANÇA DE PARADIGMA: análise sobre a efetividade das previsões atuais}

A legislação de diversos países, na tentativa de conter o avanço da taxa de congestionamento dos tribunais, tem estabelecido dispositivos destinados a incentivar soluções consensuais.

Por essa razão, na Itália, em determinadas matérias, a prévia tentativa de mediação é pressuposto processual para promoção de ação em juízo, sendo que, no curso do processo, o juiz pode reenviar as partes a um mediador. Nessa toada, embora haja motivos significantes para se questionar o problema da legitimidade constitucional da mediação compulsória, a Comissão de Estudo pela Elaboração de uma Disciplina Orgânica Voltada à Desjudicialização, presidida por Guido Alpa, conforme estabelecido pelo Ministro da Justiça Italiano, em 07 de março de 2016, com término dos trabalhos em 15 de janeiro de 2017, preferiu, por maioria, estender o período de experimentação por mais dez anos (ALPA, 2017, p. 794, 797 e 808).

Como visto, a mediação obrigatória, condicionante de uma série de litígios em matéria civil e comercial, foi estabelecida, no sistema italiano, em 2010, e reintroduzida na minirreforma do verão de 2013. Entre as demandas sujeitas à mediação obrigatória, têm-se: as questões de condomínio, direitos reais, divisão, herança, acordos familiares, locação, comodato, empresas de aluguel, causas de responsabilização médica e de saúde, demandas de seguro, contratos bancários e financeiros, além dos casos de difamação por meio da imprensa ou por outros meios (LUPOI, 2016, p. 21-22).

De igual modo, a reforma fortaleceu notavelmente o papel do juiz, que pode "convidar" as partes a iniciar a mediação, conforme a natureza do caso, o status da instrução e o comportamento das próprias partes. Esse tipo de mediação deve, por sua vez, ser considerada uma condição de procedimento, depois que o juiz a tenha ordenado (Ibid., p. 34).

A mediação e a conciliação, além de obrigatórias, devem, conforme a jurisprudência italiana, ser efetivas. Por isso parte da jurisprudência está expressando uma abordagem mais rígida, acreditando que a mera participação na primeira parte do processo de mediação (tempo dedicado à informação sobre a atividade e os métodos relacionados) não é suficiente para considerar satisfeita a condição, pois, do contrário, a tentativa de 
mediação seria reduzida a um vazio enfraquecido de simulacro, já que, não raro, nessa reunião preliminar, apenas os defensores das partes participam (Ibid., p. 24).

Nesse contexto, os tribunais têm compreendido que a mediação efetiva seria aquela em que as partes participam pessoalmente, não se podendo recorrer a qualquer forma de representação. Essa abordagem é justificada pela natureza "pessoal" das atividades a serem realizadas no processo de mediação e, no nível textual, pelo teor dos artigos 5 , parágrafo $1^{\circ}$-bis, e 8 , que dispõem que as partes passarão pelo processo de mediação com a assistência dos advogados, o que implicaria a presença dos assistidos (Ibid., p. 30).

Michele Lupoi entende, porém, que a mencionada concepção de mediação efetiva não parece ser compartilhada em nível teórico e apresenta aspectos problemáticos no âmbito operacional. A alegada inadmissibilidade da representação no processo de mediação parece estar em contradição com a natureza disponível dos direitos a que a própria mediação se aplica e com a relevância da vontade das partes em cada fase do processo. Impor, a este respeito, a (todos) os interessados o dever de estarem presentes pessoalmente pode implicar dificuldades intransponíveis e custos excessivos, incompatíveis com uma interpretação constitucional de medidas adequadas de solução de controvérsias (Ibid., p. 31-32).

Em que pese as diversas imposições mencionadas, os dados do Ministério da Justiça italiano, sobre o número de litígios civis reconciliados pelos órgãos de mediação, não parecem animadores. Desse modo, o caminho para um aprofundamento na cultura legal italiana de meios alternativos de resolução de conflitos ainda é longo (Ibid., p. 42).

Tomando-se em conta os dados estatísticos dos anos de 2016 e 2017, quanto à tendência histórica da taxa efetiva de sucesso da mediação e da conciliação, incluindo também os procedimentos em que ambas as partes apareceram apenas na primeira reunião, os números trimestrais de 2016 variaram entre 22,30\% de sucesso, com acordo atingido, no primeiro trimestre; $23,30 \%$, no segundo; $23,50 \%$, no terceiro; e $26,30 \%$, no quarto. $\mathrm{O}$ ano de 2017 iniciou em queda, com 23,70\% de êxito, passando para 26,50\%, no segundo trimestre; $26,30 \%$, no terceiro; e $25,50 \%$, no último trimestre do ano (MINISTERO DELLA GIUSTIZIA, 2017, p. 6).

A outro giro, em Portugal, a tentativa de acordo pode ser promovida de modo voluntário, em qualquer fase do processo, mediante a suspensão da instância ou sempre 
que o entenda conveniente o juiz, salvo quando uma das partes expressamente se opuser a tal remessa, conforme art. 273, n. 1 e 2, da Lei 41 de 26 de junho de 2013 (PORTUGAL, 2013a).

Ademais, conforme a Lei 78 de 13 de julho de 2001 (LJP), nas ações de conhecimento ( $\operatorname{art.} 6^{\circ}$, n. 1, LJP) cujo valor não exceda $€ 15.000$ (art. $8^{\circ}$ da LJP) e cuja matéria não seja excluída de sua competência - como ocorre nas relações envolvendo contrato de trabalho (art. $9^{\circ}$, LJP) —, a promoção do acordo pode ser desenvolvida nos julgados de paz, órgãos semelhantes aos Juizados Especiais brasileiros, responsáveis por promover a consecução dos princípios de simplicidade, adequação, informalidade, oralidade e absoluta economia processual (PORTUGAL, 2001a).

Nos julgados, após o requerimento inicial escrito ou verbal e reduzido a termo (art. 43, n. 1 a 3, LJP), e a citação para contestação (art. 47, LJP), promove-se a prémediação, salvo oposição das partes (art. 49, LJP), para avaliação da predisposição destas à resolução do conflito pela consensualidade (art. 50, n. 1, LJP). As partes devem comparecer pessoalmente aos julgados, podendo fazer-se acompanhar por advogado, advogado estagiário ou solicitador (art. 38, LJP).

Se as partes estiverem de acordo, na fase de pré-mediação, é celebrado um protocolo de mediação e agendada a primeira sessão, conduzida por profissional habilitado, cujo nome conste da lista anual (art. 33, n. 1 e 2, art. 50, n. 1, e art. 51, n. 1, LJP).

Ao contrário do que ocorre no âmbito da mediação privada, cujo acordo possui, por si só, força executiva, consoante art. $9^{\circ}$, n. 1, da Lei 29 de 19 de abril de 2013 (PORTUGAL, 2013b), nos julgados, a força obrigatória da convenção das partes depende de homologação do juiz de paz (art. 56, n. 1, LJP).

Nada obstante o caráter facultativo da mediação e da conciliação, a legislação lusitana procura estimular a consensualidade pela previsão da redução das custas judiciais das partes que alcançarem um acordo. Deveras, o uso do procedimento dos julgados de paz requer depósito do montante de $€ 35,00$ por cada uma das partes, revertendo-se em favor da parte vencedora idêntico valor, que deverá ser novamente pago, com o conhecimento da decisão final, pela parte vencida, de acordo com os arts. $2^{\circ}, 8^{\circ}$ e $9^{\circ}$ da Portaria 1.456 de 28 de dezembro de 2001 (PORTUGAL, 2001b). Entretanto, celebrado 
o acordo entre as partes, a taxa fica reduzida para $€ 50,00$, devolvendo-se a cada um dos interessados o equivalente a $€ 10,00$ (art. $7^{\circ}$ do mesmo diploma legal).

Contudo, o índice de sucesso da mediação portuguesa não é animador. Pelo contrário, houve redução na obtenção de acordos, que passou de 20\%, em 2012, para 16\%, em 2015. Semelhantemente, o índice de rejeição ao procedimento piorou, aumentando de 29\%, em 2012, para 41\%, em 2015. Quando a mediação é levada a cabo, essa tendência é, porém, revertida: o nível de eficácia da mediação foi de 59\%, em 2014; e 58\%, em 2015 (COSTA, 2017, p. 95-96), podendo-se concluir pela necessidade de promoção de uma política efetiva de incentivo à tentativa de conciliação e mediação das partes.

Por fim, em relação à prática brasileira, pode-se dizer que o Código de Processo Civil deu grande destaque para a tentativa de conciliação e mediação.

Tomando-se como parâmetro apenas o processo civil comum, sem considerações sobre o procedimento dos Juizados Especiais, o art. 334 do CPC estabelece que, estando em ordem a petição inicial, o juiz designará audiência de conciliação e mediação, a ser promovida por conciliador ou mediador inscrito em cadastro próprio (art. 167 do CPC), citando-se, para tanto, o réu.

Ao contrário da sistemática italiana, o procedimento brasileiro - assim como o português — não impõe a mediação/conciliação obrigatória. Nesse sentido, a audiência não será realizada se ambas as partes manifestarem expresso desinteresse na composição consensual - o autor, na inicial, e o réu em petição apresentada com dez dias de antecedência contados da data designada para a audiência; ou quando o direito material objeto do litígio não admitir autocomposição (art. 334, $\S \S 4^{\circ}$ e $5^{\circ}$, do CPC).

De modo similar, no Brasil, também não há espaço para aplicação do entendimento italiano sobre a mediação efetiva, já que o $§ 10$ do art. 334 do CPC é claro ao autorizar a parte a constituir representante com poderes para negociar e transigir, motivo pelo qual não é indispensável seu comparecimento pessoal.

Apesar disso, houve aumento de apenas 0,8\% no índice de conciliação de 2015 para 2016, desconsiderados os acordos elaborados em fase pré-processual. Apenas 11,9\% das sentenças e decisões proferidas no Poder Judiciário, em 2016, foram homologatórias de acordo, com destaque para a Justiça do Trabalho, que conseguiu solucionar $26 \%$ de 
seus casos por consenso - valor que aumentou para $40 \%$ quando apenas a fase de conhecimento de primeiro grau foi considerada (BRASIL, 2017, p. 125-126 e 182).

De 2016 para 2017, os dados foram desanimadores: somente 12,1\% dos processos foram solucionados por conciliação, de modo que "apesar de o novo Código de Processo Civil (CPC) tornar obrigatória a realização de audiência prévia de conciliação e mediação, em dois anos, o índice de conciliação cresceu apenas 1 ponto percentual" (BRASIL, 2018, p. 198).

\section{NORMAS INDUTORAS COMO MECANISMO DE ESTÍMULO: a sanção premial como meio de fomentar a mediação e a conciliação}

Viu-se que a simples previsão legislativa de um momento processual voltado à consensualidade não é suficiente para reverter o modelo adversarial arraigado à cultura jurídica, havendo a necessidade de fixação de incentivos outros efetivamente aptos ao estímulo comportamental desejado.

Para a Itália, a comissão presidida por Guido Alpa sugeriu a promoção dos métodos adequados de resolução de conflitos mediante concessões fiscais, incluindo a economia de despesas e a estipulação de medidas de recompensa. Relativamente aos incentivos, sugeriu-se ao Ministro da Justiça Italiano a previsão - considerada essencial pela comissão - de elevação da isenção do imposto de registro da ata até o limite de $€$ 100.000,00 para as mediações endoprocessuais, após avaliação do juiz, a fim de eliminar ou reduzir o risco de comportamento negocial elusivo ou simulado (ALPA, 2017, p. 808809).

Essa sugestão, no que toca aos incentivos fiscais, também pode ser interessante para o modelo português e - no que interessa mais de perto para os fins deste trabalho — o brasileiro.

Decerto, o uso de normas tributárias com finalidades outras para além da simples arrecadação fiscal não é uma novidade no Brasil. O critério teleológico de interpretação das normas, de acordo com o qual a hermenêutica deve se ocupar da finalidade imanente ao conteúdo normativo, isto é, ao escopo para o qual a regra ou o princípio foi concebido, casa-se perfeitamente com a noção de normas tributárias indutoras.

Na prática, essa modalidade de norma fiscal funciona pela associação a uma determinada conduta de uma consequência positiva ou negativa sob a ótica da carga 
tributária. Ora, tendo a norma de indução o objetivo de atuar mediante estímulos e desestímulos, que devem ser tomados em conta para a adequada fixação do sentido da lei, o exame teleológico se lhe apresenta essencial (SCHOUERI, 2005, p. 30 e 54).

Portanto, o recurso ao argumento da finalidade e ao método teleológico de interpretação, na seara tributária, referem-se justamente aos casos em que as normas tenham funções eficaciais outras que não a mera arrecadação (CORREIA NETO, 2013, p. 72).

Entre as diversas modalidades de normas indutoras, estão as exonerações tributárias, que são modos de não tributação intencional, nomeadas de "incentivos fiscais" quando ostentam fins extrafiscais, mediante encorajamento de certas condutas ou objetivos (CORREIA NETO, 2016, p. 26-28).

Pragmaticamente, as normas indutoras podem ser conceituadas como normas tributárias dotadas de função indutora, já que vinculam um comportamento a uma oneração ou desoneração fiscal (SCHOUERI, 2005, p. 30). Nesse último caso, há, claramente, um estímulo a determinado comportamento, induzido pela legislação, ao passo que, no primeiro, visa-se coibir condutas.

Com efeito, Norberto Bobbio foi um dos pioneiros no destaque da função promocional do Direito, em oposição a sua concepção necessária ou predominantemente repressiva, de sanção como uma consequência negativa. Nesse campo, ao invés de uma ameaça, a norma apresenta uma promessa: o comportamento desejado se torna mais fácil ou, "uma vez praticado, é seguido por medidas que pretendem a sua retribuição". Há uma importância crescente das sanções positivas para o Direito, que cada vez mais deixa de atuar nas funções de comando, controle e vigilância, dando espaço ao gênero "influência" no lugar do gênero "coação" (BOBBIO, 2007, p. 7, 19, 26 e 31-32).

Ainda acerca das funções promocional e coativa da ordem jurídica, é certo que o encorajamento ou o desincentivo a determinada prática, ao revés da sanção — positiva ou negativa - não depende da prévia existência de uma norma impositiva de um dever contraposto a uma reação institucional. O incentivo ou a dissuasão, na primeira hipótese, não são acessórios ou derivados, mas finalidades normativas primaciais (Ibid., p. 72).

Por certo, a natureza das normas é prescritiva, sendo sua tarefa não a descrição de consequências derivadas de fatos, mas a de colocá-las em ação (BOBBIO, 2001, p. 
142). A atuação por meio de estímulos e desincentivos é precisamente o modus operandi das normas de indução (SCHOUERI, 2005, p. 54).

No caso das desonerações tributárias para incentivo à consensualidade, conforme proposta deste trabalho, o encorajamento seria à utilização de meios adequados à solução de conflitos diversos da jurisdição estatal, estimulando que as partes estejam em condições psicologicamente favoráveis à obtenção de um acordo. Assim, se se cria um benefício fiscal em favor de uma delas, esta poderá ser levada a formular um bom acordo para a outra, de modo a que o litígio chegue a um bom termo.

Essa sistemática é utilizada, por exemplo, em programas de recuperação fiscal (Refis), mediante regimes opcionais de parcelamentos de débitos tributários em condições diferenciadas, como o Programa de Regularização Tributária (PRT), estabelecido pela Medida Provisória 766 de 4 de janeiro de 2017, e o Programa Especial de Regularização Tributária (PERT), instituído pela Lei 13.496 de 24 de outubro de 2017; no regime de arrecadação especial do Simples Nacional, em favor de Micro e Pequenas Empresas, nos termos da Lei Complementar 123 de 14 de dezembro de 2006; no regime especial de tributação das incorporações imobiliárias que adotem o regime do patrimônio de afetação, pagando-se apenas 1 ou $4 \%$ da receita mensal recebida, conforme critérios do art. $4^{\circ}$ da Lei 10.931 de 02 de agosto de 2004 e em várias outras searas do Direito.

Poder-se-ia imaginar, portanto, a criação de um regime tributário especial, com duração de um ano, em favor de grandes litigantes, que sejam acionados com frequência no sistema de Justiça, caso finalizem certo percentual de seus processos em curso, mediante o estabelecimento de acordos, a perdurar no ano seguinte à constatação do número de acordos necessários a atrair o sistema tributário diferencial.

Veja-se que, com isso, não é necessário que o regime especial seja oferecido a todas as partes, basta que o seja a ao menos uma delas e que seja interessante o suficiente para convencê-la de propor à outra um acordo razoável.

Igualmente, pode-se conceber a previsão de um percentual fixo de dedução no imposto sobre a renda, em favor do réu ou executado que efetua um pagamento voluntário, antes de oferecer resistência à pretensão do autor ou exequente, em situações específicas. São, de fato, ilimitadas as opções legislativas para a promoção da consensualidade nessas hipóteses. 
Para finalizar, deve-se afirmar que não necessariamente tais concessões fiscais representariam simples renúncias de receita pelo Estado.

O Centro de Pesquisas sobre o Sistema de Justiça Brasileiro (CPJus) do Instituto Brasiliense de Direito Público (IDP) elaborou um estudo, embasado no relatório "Justiça em Números" do Conselho Nacional de Justiça, em que constatou ser o custo médio do processo, em 2013, equivalente a $\mathrm{R} \$ 2.369,73$ (CENTRO DE PESQUISAS SOBRE O SISTEMA DE JUSTIÇA BRASILEIRO - CPJus, 2014, p. 8 e 39, tabela 19).

Tomando-se por base tal montante, para a concessão de um incentivo fiscal que seja, além de frutífero à promoção do desejável estímulo à cultura da consensualidade, interessante em termos quantitativos para o Estado, bastaria estabelecer um regime tributário especial cuja redução esperada de arrecadação seja inferior à economia estimada com o custo do processo, acompanhada de alguma medida de repasse de valores do Poder Judiciário em prol dos entes federativos cuja arrecadação seja reduzida em decorrência do incentivo fiscal.

\section{CONSIDERAÇÕES FINAIS}

As estatísticas do Judiciário demonstram um aumento crescente no número de processos em tramitação no sistema de Justiça brasileiro, que subiu de 74 milhões, em 2015, para 79,7 milhões, em 2016, e, finalmente, 80,1 milhões, em 2017, havendo clara dificuldade de gestão desses quantitativos pelo uso dos métodos atuais. Esses e outros dados conduzem à necessidade de amenização da cultura de litigiosidade, no Brasil, e ao incentivo ao uso de métodos adequados à resolução de litígios, como a conciliação e a mediação.

No entanto, a promoção da consensualidade encontra resistência social e até mesmo hostilidade em meio à classe forense. Entende-se que a reversão desse quadro, embora, em parte, dependente de uma mudança no sistema de ensino jurídico, pressupõe o desenvolvimento de uma cultura autocompositiva.

A tentativa de incentivar soluções consensuais não é uma realidade exclusiva da legislação nacional. Na Itália, por exemplo, a prévia tentativa de mediação/conciliação foi instituída como pressuposto processual para a promoção de ação em juízo, em determinadas matérias. Ainda assim, a restrita efetividade da medida para a resolução dos litígios demanda a busca por outros meios de incentivo ao acordo. 
Igualmente, em Portugal, as mudanças legislativas caminham no sentido da promoção da autocomposição. Assim, por exemplo, a criação do procedimento diferenciado para os julgados de paz. Nada obstante, o índice de sucesso da mediação portuguesa demonstra queda.

No Brasil, embora a tentativa de composição voluntária das partes não seja obrigatória, pode-se dizer que o Código de Processo Civil não poupou esforços para a promoção da mediação e da conciliação, prevendo fase processual específica para a sua realização. Apesar disso, o aumento do índice de casos resolvidos por acordo foi de apenas $0,8 \%$ de 2015 para 2016, havendo crescimento de apenas um ponto percentual no índice de conciliação, em dois anos, até 2017, a despeito da vigência do novo CPC.

Por todo o exposto, torna-se necessário fixar medidas de real encorajamento ao consenso. Não por outro motivo, a Comissão de Estudo pela Elaboração de uma Disciplina Orgânica Voltada à Desjudicialização, constituída na Itália, sugeriu a adoção de concessões fiscais para o incentivo ao uso dos métodos adequados de solução de controvérsias - o que também parece ser um caminho interessante para o Brasil.

O uso de normas tributárias com a finalidade de induzir comportamentos, fixando-se sanções premiais para condutas consideradas desejáveis pela ordem jurídica, não é uma novidade no país. Poder-se-ia, assim, estabelecer um regime tributário especial, válido pelo ano seguinte àquele no qual um litigante contumaz, nas ações em que é demandado, obtiver a composição por meio de acordo, em um determinado percentual dos processos nos quais é parte.

Tomando-se como base o custo do processo à Justiça Brasileira, da ordem de $\mathrm{R} \$$ 2.369,73, em 2013, essa previsão poderia ser interessante não apenas sob o aspecto do estímulo à cultura de mediação/conciliação, mas também em termos econômicos. Destarte, poder-se-ia estabelecer um sistema em que a redução fiscal seja atrativa frente à economia de recursos do Poder Judiciário, bem como fixar um mecanismo de repasse de valores deste ao Executivo dos entes federativos cuja arrecadação seja reduzida como resultado do incentivo fiscal.

\section{REFERÊNCIAS}


ALPA, Guido. Commissione di studio per l'elaborazione di uma orgânica disciplina volta ala "degiurisdizionalizzazione". In: Rivista Trimestrale di Diritto e Procedura Civile, Anno LXXI, N. 2, p. 793-813, jun. 2017.

AMORIM, Aureliano Albuquerque. A relação entre o sistema arbitral e o Poder Judiciário. 2. ed. Belo Horizonte: Fórum, 2011.

ANDRADE, Érico. A contratualização do processo. In: Fernando Gonzaga Jayme, Gláucio Maciel Gonçalves, Juliana Cordeiro de Faria, Marcelo Veiga Franco, Mayara de Carvalho Araújo, Suzana Santi Cremasco. (Org.). Processo Civil Brasileiro - Novos Rumos a partir do CPC/2015. Belo Horizonte: Del Rey Editora, p. 47-65, 2016.

ARAÚJO, Mayara de Carvalho. O novo regramento da autocomposição de conflitos. In: Fernando Gonzaga Jayme, Gláucio Maciel Gonçalves, Juliana Cordeiro de Faria, Marcelo Veiga Franco, Mayara de Carvalho Araújo, Suzana Santi Cremasco. (Org.). Processo Civil Brasileiro - Novos Rumos a partir do CPC/2015. Belo Horizonte: Del Rey Editora, p. 91- 101, 2016.

BACELLAR, Roberto Portugal. Nas soluções autocompositivas o juiz não está limitado, nem deve ficar adstrito, ao pedido e à contestação. In: Revista da Escola Nacional da Magistratura, Ano 7, N. 6, p. 86-89, nov. 2012a. Disponível em: <http://www.enm.org.b r/dos/ENM_6.pdf>. Acesso em: 18 jun. 2018.

Nos modelos consensuais autocompositivos (conciliação, mediação) não há produção de provas. In: Revista da Escola Nacional da Magistratura, Ano 7, N. 6, p. 90-91, nov. 2012b. Disponível em: 〈http://www.enm.org.br/docs/ENM_6.pdf〉. Acesso em: 18 jun. 2018.

BOBBIO, Norberto. Da estrutura à função: novos estudos de Teoria do Direito. Trad. Daniela Beccaccia Versiani. Barueri, SP: Manole, 2007.

Teoria da norma jurídica. Trad. Fernando Pavan Baptista e Ariani Bueno Sudatti. Bauru, SP: EDIPRO, 2001.

BONATO, Giovanni. Arbitragem societária italiana: análise comparativa sobre a abrangência subjetiva da cláusula compromissória e a nomeação dos árbitros. In: Revista da arbitragem e mediação, Ano 12, V. 46, p. 337-358, jul./set. 2015. 
BRASIL, Conselho Nacional de Justiça. Justiça em números 2016: ano-base 2015. Brasília: CNJ, 2016. Disponível em: <http://www.cnj.jus.br/files/conteudo/arquivo/201 6/10/b8f46be3dbbff344931a933579915488.pdf>. Acesso em: 15 jun. 2018.

Justiça em números 2017: ano-base 2016. Brasília: CNJ, 2017. Disponível em: <http://www.cnj.jus.br/files/conteudo/arquivo/2017/12/b60a659e5d5cb79337945c1dd1 37496 c.pdf >. Acesso em: 16 jun. 2018.

Justiça em números 2018: ano-base 2017. Brasília: CNJ, 2018. Disponível em: <http://www.cnj.jus.br/files/conteudo/arquivo/2018/09/8d9faee7812d35a58cee3d92d2d f2f25. pdf $>$. Acesso em: $1^{\circ}$ maio 2019.

CALMON, Petrônio. Fundamentos da mediação da conciliação. 3. ed., Brasília: Gazeta Jurídica, 2015.

CENTRO DE PESQUISAS SOBRE O SISTEMA DE JUSTIÇA BRASILEIRO (CPJus). Índice de desempenho da Justiça: IDJus 2013 e estudo comparado sobre a evolução do Judiciário 2010-2013. Brasília, dez. 2014. Disponível em: <http://cpjus.idp.edu.br/wp-co ntent/uploads/2015/03/IDJUSn4_relatorio_pesquisa_23 .02.15.pdf >. Acesso em: 27 jun. 2018.

CORREIA NETO, Celso de Barros. O avesso do tributo: incentivos e renúncias fiscais no direito brasileiro. 2. ed., São Paulo: Almedina, 2016.

; MEIRA, Liziane Angelotti. Métodos de interpretação e Direito Tributário. Revista do Programa de Pós-Graduação em Direito da UFC, V. 33.2, p. 53-82, jul./dez. 2013. Disponível em: <http://www.periodicos.ufc.br/index.php/nomos/article/d ownload/988/959. >. Acesso em: 25 jun. 2018.

COSTA, Elisabete Pinto. A mediação de conflitos em Portugal. Sistemas públicos de mediação (familiar, penal, laboral e nos julgados de paz) e mediação privada, 2017. Disponível em: <https://www.researchgate.net/publication/322069184_A_mediacao_de _conflitos_em_Portugal_Sistemas_publicos_de_mediacao_familiar_penal_laboral_e_no s_Julgados_de_Paz_e_mediacao_privada>. Acesso em: 24 jun. 2018.

DEOLINDO, Vanderlei. Medidas a serem adotadas pela AMB junto às instituições de ensino jurídico do país. In: Revista da Escola Nacional da Magistratura, Ano 7, N. 6, p. 83-85, von. 2012. Disponível em: <http://www.enm.org.br/docs/ENM_6.pdf>. Acesso em: 18 jun. 2018. 
GONÇALVES, Gláucio Ferreira Maciel. Acesso à Justiça e reforma do Judiciário. In: RODRIGUES, Horácio Wanderlei; GONÇALVES, Gláucio Ferreira Maciel; LYNCH, Christian Edward Cyril; VERONESE, Alexandre; SANTOS, Rogério Dultra dos. O terceiro poder em crise: impasses e saídas. Rio de Janeiro: Fundação Konrad Adenauer, p. 55-70, 2003.

BRITO, Thiago Carlos de Souza. Gerenciamento dos processos judiciais: notas sobre a experiência processual civil na Inglaterra pós-codificação. In: Revista Fac. Direito UFMG. Belo Horizonte, N. 66, p. 291-326, jan./jun. 2015. Disponível em: <https ://www.direito.ufmg.br/revista/index.php/revista/article/view/1697/1612>. Acesso em: 15 jun. 2018.

LUPOI, Michele Angelo. Ancora sui rapporti tra mediazione e processo civile, dopo le ultime riforme. In: Rivista Trimestrale di Diritto e Procedura Civile, Anno LXX, N. 1, p. 13-42, mar. 2016.

MINISTERO DELLA GIUSTIZIA. Direzione Generale di Statistica e Analisi Organizzativa. Mediazione civile ex D.L. 28/2010: statistiche del 2017. Disponível em: $<$ https://webstat.giustizia.it/Analisi\%20e\%20ricerche/Mediazione\%20Civile\%20-Anno $\% 202$ 017.pdf>. Acesso em: 20 jun. 2018.

ORSINI, Adriana Goulart de Sena; NEVES, Natália de Souza. O diálogo nas práticas restaurativas: a (re)compreensão do passado através da linguagem. In: ORSINI, Adriana Goulart de Sena; VASCONCELOS, Antônio Gomes de (Coord.). Acesso à justiça. Belo Horizonte: Initia Via, p. 28-44, 2012. Disponível em: <https://static1.squarespace.com/s tatic/5595888ae4b0f75fd292e2d6/t/559705d8e4b0892edbf9cfdf/1435960792934/S01V 02_Orsini+\%26+Vasconcelos+-+Acesso+\%C3\%A0+justi\%C3\%A7a++Initia+Via.pdf $>$. Acesso em: 16 jun. 2018.

PORTUGAL. Código de Processo Civil. Lisboa: Assembleia da República, 2013a. Disponível em: <http://www.pgdlisboa.pt/leis/lei_print_articulado.php?tabela=leis\&arti go_id=\&nid=1959\&nversao=\&tabela=leis >. Acesso em: 21 jun. 2018.

Lei dos Julgados de Paz. Lisboa: Assembleia da República, 2001a. Disponível em: <http://www.pgdlisboa.pt/leis/lei_mostra_articulado.php?artigo_id=724A0001\&nid $=724 \&$ tab ela $=$ leis\&pagina $=1 \&$ ficha $=1 \&$ so_miolo=\&nversao=\#artigo $>$. Acesso em: 22 jun. 2018. 
Lei dos Princípios Gerais Aplicáveis à Mediação - Mediação Civil e Comercial. Lisboa: Assembleia da República, 2013b. Disponível em: <http://www.pgdlis boa.pt/leis/lei_mostra_articulado.php?nid=1 907\&tabela=leis>. Acesso em: 23 jun. 2018.

Portaria das Custas Judiciais nos Julgados de Paz. Lisboa: Ministério da Justiça, 2001b. Disponível em: <http://www.pgdlisboa.pt/leis/lei_mostra_articulado.php?nid $=849 \&$ tabela=leis $>$. Acesso em: 23 jun. 2018.

SCHOUERI, Luís Eduardo. Normas tributárias indutoras e intervenção econômica. Rio de Janeiro: Forense, 2005. 